\title{
Relevanz des NMP22-Schnelltests für das Harnblasenkarzinom
}

\author{
Für die Frühdiagnostik des Harnblasenkarzinoms \\ existieren bisher keine Modelle, um das individuelle \\ Risiko quantitativ abschätzen zu können. Amerika- \\ nische Kollegen prüften nun den Nutzen des \\ NMP22-Tests bei Hochrisikopersonen für diese \\ Fragestellung.
}

$\mathrm{D}$ ie Arbeitsgruppe um Yair Lotan von der Univerität von Texas in Dallas beurteilten retrospektiv insgesamt 1.272 Patienten. Jedem wurde ein hohes Risiko bescheinigt. Alle litten unter Dysurie und/oder Hämaturie und sie waren mindestens 10 Jahre lang selbst starke Raucher gewesen oder solchen ausgesetzt. Von den 1.272 Patienten konnte bei 217 $(17,1 \%)$ eine erhöhte Konzentrationen des tumorassoziierten nukleären Matrixproteins 22 (NMP22) nachgewiesen werden, bei $17(1,3 \%)$ lag ein auffälliger urinzytologischer Befund vor, und 76 (6\%) hatten ein zystoskopisch nachgewiesenes Harnblasenkarzinom.

Die Forscher entwickelten aus den Daten von 670 dieser Patienten Nomogramme auf der Basis verschiedener multivariater Regressionsmodelle, in denen NMP22, bestimmt mit einem Schnelltest, Hauptprädiktor war. Patientencharakteristika wie Alter, Geschlecht, Rasse, Raucherstatus sowie Vorhandensein oder Nicht-Vorhandensein von Makro- bzw. Mikrohämaturie fungierten als Kovariablen. In dem multivariaten Modell, das die Urinzytologie mit berücksichtigte, war diese ein unabhängiger Prädiktor $(\mathrm{p}=0,007)$ : Ein positiver Befund in der zytologischen Diagnostik bedeutete eine 23,5-fach erhöhte Tumor- wahrscheinlichkeit. Wenn alle Faktoren gemeinsam betrachtet wurden, erwiesen sich die Zytologie ebenso wie der NMP22-Wert als unabhängige Risikofaktoren.

Bei der Validierung der Modelle anhand der übrigen 602 Patienten mittels AUCWerten ergab sich für die NMP22-Resultate als isolierter Befund ein Wert von $76,0 \%$ - gegenüber nur $56,2 \%$ für die Zytologie ( $\mathrm{p}<$ $0,001)$; in Kombination mit allen anderen Kovariablen betrugen die Quoten 82,4 resp. 74,7\% ( $\mathrm{p}=0,006)$. Damit ist die Aussagekraft der Zytologie limitiert, während der NMP22-Test sich als signifikant besser prädiktiv erwies.

Fazit: Der NMP22-Test sagt das Vorliegen eines Blasenkrebses bei Hochrisikopersonen signifikant besser voraus als die Urinzytologie, so das Urteil der Autoren. Zusammen mit Daten zu anderen Risikofaktoren kann der Test Patienten mit hohem Risiko identifizieren. wpa

Lotan $Y$ et al. Impact of clinical factors, including a point-ofcare nuclear matrix protein-22 assay and cytology, on bladder cancer detection. BJU Int 2009; 103: 1368-74. 